\title{
Investigating the Impact of Some Habitat Characteristics on Distribution of Stachys pilifera Benth Using the BMLR Model in Iran
}

\author{
Shahab Mirinejad ${ }^{1}$, Esfandiar Jahantab ${ }^{2 *}$, Mohammad Reza Mahmoudi ${ }^{3}$, \\ Mehrdokht Najafpour Navaei ${ }^{4}$, Mohammad Mehdi Rahimi ${ }^{5}$, \\ Mohsen Sharafatmandrad ${ }^{6}$ \\ ${ }^{1}$ Research Division of Natural Resources, Kohgiluyeh and Boyerahmad Agricultural and Natural Resources \\ Research and Education Center, AREEO, Yasooj, Iran \\ ${ }^{2}$ Department of Range and Watershed Management, Faculty of Agricultural Sciences, Fasa University, Fasa, Iran \\ ${ }^{3}$ Department of Statistics, Faculty of Science, Fasa University, Fasa, Iran \\ ${ }^{4}$ Research Institute of Forests and Rangelands, Agricultural Research, Education and Extension Organization (AREEO), \\ Tehran, Iran \\ ${ }^{5}$ Department of Agronomy, Arsanjan Branch, Islamic Azad University, Arsanjan, Iran \\ ${ }^{6}$ Faculty of Natural Resources, University of Jiroft, Jiroft, Iran
}

Received: 6 July 2017

Accepted: 2 November 2017

\begin{abstract}
Stachys pilifera is an endemic plant to Iran. The main purpose of this study was to investigate the impacts of some habitat characteristics on the distribution of S. pilifera using the BMLR model in Kohgiluyeh and Boyer-Ahmad Province, Iran. Tow transects were randomly established in each region. 10 quadrats sized $1 \times 1 \mathrm{~m}^{2}$ were established along the transect. In each plot, canopy cover (\%) of S. pilifera was recorded. 25 soil samples were gathered in the region to evaluate soil characteristics. The associated pixel of each plot was extracted and added to a prepared spreadsheet of a field database. The data gathered from experiments were fed into the computer item by item according to their own values. To determine the effect of environmental factors on the distribution of S. pilifera species, the researchers run a set of backward multiple linear regressions. The results of MLR to investigate the significance of was not significant (P-Value $>0.05$ ). Then the most insignificant term in the first run (silt) is removed and the operation run again. After removing silt, the results of the BMLR model are seen by considering the effect of other factors, and some of terms are insignificant again. The process is continued step by step to the point that there are only significant terms. Results showed that the effects of rain, sand, $\mathrm{P}, \mathrm{Fe}, \mathrm{Zn}, \mathrm{Mn}$, and evaporation on the distribution of S. pilifera species were significant. Rain, P, and Fe have positive effects (positive coefficient), while sand, $\mathrm{Zn}, \mathrm{Mn}$, and evaporation have negative effects (negative coefficient).
\end{abstract}

*e-mail: e.jahantab@ut.ac.ir 
Results showed that the BMLR appropriately modeled the canopy cover of S. pilifera based on RMSE, $R^{2}$, and , which were $0.999,0.998$, and 2.1395 , respectively.

Keywords: Stachys pilifera, habitat characteristics, BMLR model

\section{Introduction}

The genus Stachys (Lamiaceae) contains about 300 species and is extensively distributed in tropical and subtropical countries [1]. This genus in Iran is represented by 34 species, 13 of which are endemic. Stachys pilifera Benth is one of the endemic species to Iran. Stachys pilifera is a fruticose and pragnant perennial herbaceous plant of the Lamiaceae family. This plant species can be found in mountainous habitats, especially moist areas that are affected by humidity resulting from surface or subsurface waters. The plant has a short stem covered with simple and slender leaves, pink to white flowers that all aerial organs have a pleasant and distinctive smell (an aromatic compound). There are many studies on essential oil of this plant. Cis-chrysanthenyl acetate (25.2\%) and trans-verbenol $(19.7 \%)$ are the main compounds in the essential oil of Stachys pilifera.

The aerial organs of the plant are used in Iranian traditional medicine as herbal tea for the treatment of various diseases such as asthma and rheumatoid arthritis, plus infections [2]. A biological study has shown the potent antioxidant, antimicrobial, and antitumor activities of the n-butanolic extract of $S$. pilifera in in-vitro conditions [3].

Although there are many studies about environmental factors controlling plant distribution of endemic and endangered plant species [4-7], this kind of knowledge on S. pilifera is rare. For example, the distribution map of S. pilifera in Central Zagros in the Kohgiluyeh Region is prepared, and its autecology is determined [8]. Studying the cultivation possibility of S. pilifera showed that lowland ecotypes have more capability for greenhouse cultivation and that these ecotypes have more essential oil [9]. Phonological studies indicate that $S$. pilifera starts to germinate in mid-April and continues to vegetative growth until June; inflorescences appears in late June and seeds will mature until late September [8].
As mentioned above, there are not many studies about the relationship between $S$. pilifera and controlling environmental factors. Therefore, studying the environmental requirements of this plant species is important. The main purpose of this study is to evaluate the impact of habitat characteristics on the distribution of S. pilifera using the BMLR model in Kohgiluyeh and Boyer-Ahmad Province, Iran.

\section{Material and Methods}

\section{Study Area}

This study was carried out on Kohgiluyeh and BoyerAhmad Province in central Zagros in southwestern Iran. The S.pilifera habitats were determined by asking experts and local people and also field investigations. Thus, S.pilifera habitats were clarified and separated as one of the sampling points. Detailed information about each habitat is presented in Table 1 .

\section{Data Collection}

Habitat characteristics of the S.pilifera species were determined in order to achieve behavior and environmental conditions. Therefore, vegetation and different environmental factors including topography, pedology, and climatic characteristics were measured.

Tow transects were randomly established in each region. Ten $1 \times 1 \mathrm{~m}$ quadrats were established along each transect. The recorded parameter in each quadrat was S. pilifera canopy cover (\%). The location of each quadrat was recorded with GPS. 25 soil samples were taken (5 samples in each habitat) in order to identify soil characteristics such as EC [10], $\mathrm{pH}$ [11], organic matter [12], soil texture [13], P [14], N [10], K [15], $\mathrm{Mn}, \mathrm{Cu}$, $\mathrm{Zn}$, and Fe [16]. For climatological and land shape data, the height, slope and aspect maps were generated by creating DEM. The associated pixel values of each plot

Table 1. Detailed information about S.pilifera habitats in Kohgiluyeh and Boyer-Ahmad Province in central Zagros.

\begin{tabular}{|c|c|c|c|c|}
\hline Habitat & Longitude & Latitude & Mean elevation (m asl) & Dominant vegetation type \\
\hline Pazanan Sepidar & $30^{\circ} 32^{\prime} 9.3^{\prime \prime}$ & $51^{\circ} 29^{\prime} 8.1^{\prime \prime}$ & 2575 & Prangos uloptera \\
\hline Delon Sisakht & $30^{\circ} 52^{\prime} 11.1^{\prime \prime}$ & $51^{\circ} 28^{\prime} 54.9^{\prime \prime}$ & 2585 & Daphne mucronata \\
\hline $\begin{array}{c}\text { Road of Margon to } \\
\text { Lodab }\end{array}$ & $30^{\circ} 58^{\prime} 35.3^{\prime \prime}$ & $51^{\circ} 2^{\prime} 32.1^{\prime \prime}$ & 2090 & Gundelia turnefortii \\
\hline Vezg & $30^{\circ} 30^{\prime} 24.5^{\prime \prime}$ & $51^{\circ} 42^{\prime} 33.4^{\prime \prime}$ & 2420 & Dorema aucheri \\
\hline Chin village & $31^{\circ} 5^{\prime} 20.8^{\prime \prime}$ & $51^{\circ} 48^{\prime} 38.2^{\prime \prime}$ & 2415 & Prangos Sp \\
\hline
\end{tabular}


were extracted and added to a prepared spreadsheet of field database.

\section{Data Analysis}

A set of backward multiple linear regressions were run to determine the effect of environmental factors on the distribution of $S$. pilifera species. The KolmogorovSmirnov test was applied to verify the normality of canopy cover. This condition is an essential condition for using the parametric methods as BMLR. Canopy cover had normal distribution. Therefore, parametric methods can be applied for statistical analysis. Regression analysis generates an equation to describe the statistical relationship between canopy cover and environmental factors. Regression results indicate the direction, size, and statistical significance of the relationship between canopy cover and environmental factors. The sign of each coefficient indicates the direction of the relationship. Coefficients represent the mean change in canopy cover for one unit of change in one environmental factor while holding other environmental factors in the model constant. P-value for each coefficient tests the null hypothesis that the coefficient is equal to zero (no effect). Therefore, low p-values suggest that one environmental factor is a meaningful addition to the model.

In MLR, variables were removed and added to the regression model for the purpose of identifying a useful subset of environmental factors (the predictors). Multiple linear regression (MLR) is a flexible method of data analysis that may be appropriate whenever a quantitative variable (the dependent or response variable) is to be examined in relationship to any other factors $\left(X_{1}\right.$, $X_{2}, \ldots, X_{k}$ - the independent or explanatory or predictor variables). The general equation of MLR is presented by

$$
Y_{i}=\beta_{0}+\beta_{1} X_{1 i}+\beta_{2} X_{2 i}+\ldots+\beta_{k} X_{k i}+\varepsilon_{i}
$$

...for $n$ observations $n=1, \ldots, n$,

...where $\beta_{0}, \beta_{1}, \ldots, \beta_{k}$ are model parameters (coefficients) and $\varepsilon_{i}, i=1, \ldots, n$, are the random components of the model that follow independent normal distributions with mean 0 and variance $\sigma^{2}$.

The dataset is used to estimate the coefficients $\beta_{0}, \beta_{1}, \ldots, \beta_{k}$. The general equation of the predictive MLR model is presented by

$$
\hat{Y}_{i}=b_{0}+b_{1} X_{1 i}+b_{2} X_{2 i}+\ldots+b_{k} X_{k i}
$$

...where $b_{0}, b_{1}, \ldots, b_{k}$ are estimations of model parameters, and $\hat{Y}_{i}$ is the predicted value of $Y_{i}$.

The MLR model can be rewritten in matrix form

$$
\boldsymbol{Y}=\boldsymbol{X} \boldsymbol{\beta}+\varepsilon
$$

...where $\boldsymbol{Y}=\left(y_{1}, \ldots, y_{n}\right)^{T}$ is vector of responses, $X$ is a $n \times(k+1)$ full rank design matrix with the first column given by $(1, \ldots, 1)^{T}$, and the $l^{\text {th }}(2 \leq l \leq k+1)$ column given by, $\left(x_{l-1,1}, \ldots, x_{l-1, n}\right)^{T}, \boldsymbol{\beta}=\left(\beta_{0}, \ldots, \beta_{k}\right)^{T}$ is vector of unknown parameters, and $\varepsilon=\left(\varepsilon_{1}, \ldots, \varepsilon_{n}\right)^{T}$ is vector of random errors. Also $\hat{\boldsymbol{Y}}=X \boldsymbol{b}$, where $\hat{\boldsymbol{Y}}=\left(\hat{y}_{1}, \ldots, \hat{y}_{n}\right)^{T}$ is vector of predicted values, and $\boldsymbol{b}=\left(b_{0}, \ldots, b_{k}\right)^{T}$ is vector of coefficients. We note that in the model without interception $\left(\beta_{0}=0\right)$, column $(1, \ldots, 1)^{T}$ should be removed from matrix $X$.

The ordinary least squares (Maximum Likelihood) estimation of the coefficient vector $\boldsymbol{\beta}$ is given by:

$$
\boldsymbol{b}=\left(X^{T} X\right)^{-1} X^{T} \boldsymbol{Y}
$$

This is a common approach, and it assumes that there are enough measurements to say something meaningful about $\boldsymbol{\beta}$.

As can be seen, the MLR model contains linear effects of $X_{1}, X_{2}, \ldots, X_{k}$. But perhaps some of these effects are not significant (P-Value $>0.05$ ). In this case, the backward method (BMLR) is used and the ineffective parameters are removed gradually. The final model has parsimonious accurate parameters. The statistical BMLR model was applied using $\mathrm{R}$ and Minitab software.

Table 2. Descriptive statistics of environmental variables for all S. pilifera.

\begin{tabular}{|c|c|c|c|c|c|}
\hline & $\mathrm{N}$ & $\begin{array}{c}\text { Mini- } \\
\text { mum }\end{array}$ & $\begin{array}{c}\text { Maxi- } \\
\text { mum }\end{array}$ & Mean & $\begin{array}{c}\text { Std. } \\
\text { Deviation }\end{array}$ \\
\hline Elevation & 25 & 2,078 & 2,595 & $2,424.68$ & 181.794 \\
\hline Rain & 25 & 766 & 964 & 887.68 & 69.916 \\
\hline Temperature & 25 & 11 & 20 & 14.60 & 4.113 \\
\hline $\mathrm{PH}$ & 25 & 7.10 & 7.35 & 7.1888 & .07020 \\
\hline $\mathrm{EC}$ & 25 & .32 & 1.88 & .7364 & .49942 \\
\hline $\begin{array}{c}\text { OC (organic } \\
\text { matter) }\end{array}$ & 25 & 1.07 & 2.97 & 2.0092 & .60643 \\
\hline Clay & 25 & 28 & 46 & 36.28 & 5.144 \\
\hline $\mathrm{Silt}$ & 25 & 50 & 65 & 56.08 & 3.696 \\
\hline Sand & 25 & 3 & 15 & 7.76 & 2.554 \\
\hline $\mathrm{K}$ & 25 & 194 & 529 & 327.28 & 112.316 \\
\hline $\mathrm{P}$ & 25 & 4.22 & 19.96 & 13.0208 & 6.25604 \\
\hline $\mathrm{N}$ & 25 & .10 & .85 & .3091 & .25617 \\
\hline $\mathrm{Fe}$ & 25 & 8.17 & 19.80 & 14.1928 & 4.03759 \\
\hline $\mathrm{Zn}$ & 25 & .19 & 1.50 & .6336 & .47668 \\
\hline $\mathrm{Cu}$ & 25 & .40 & 1.22 & .8072 & .24234 \\
\hline $\mathrm{Mn}$ & 25 & 5.37 & 14.49 & 10.9112 & 3.00740 \\
\hline Humidity & 25 & 52 & 63 & 58.80 & 4.537 \\
\hline Evaporation & 25 & 1,458 & 1,803 & $1,597.96$ & 149.574 \\
\hline $\begin{array}{c}\text { Canopy } \\
\text { cover }\end{array}$ & 25 & 43 & 68 & 55.36 & 6.720 \\
\hline
\end{tabular}




\section{Results and Discussion}

\section{Descriptive Statistics}

Descriptive statistics of measured variables are shown in Table 2.

\section{Important Factors on Distribution of S. pilifera Species}

In order to evaluate the importance of different environmental factors on the distribution of S. pilifera, its canopy cover was considered as the response variable. Also, the other variables were continuous predictor variables. The general equation of MLR was presented by

$$
\begin{gathered}
\text { Canopy Cover }{ }_{i}=\beta_{0}+\beta_{1} \text { Elev }_{i} \\
+\ldots+\beta_{18} \text { Evapo }_{i}+\varepsilon_{i}
\end{gathered}
$$

First, all terms were entered and created the model. Table 4 shows the results of MLR to investigate the significance of $\beta_{0}$. As can be seen in Table 4, intercept (constant) was not significant (P-Value $>0.05$ ). In other words, the model didn't need $\beta_{0}$.

\begin{tabular}{|c|c|c|}
\hline & Coefficient & P-Value \\
\hline Constant & -24.6421 & 0.993 \\
\hline Elevation & 0.0636 & 0.631 \\
\hline Rain & 0.7317 & 0.132 \\
\hline Temperature & 3.5585 & 0.918 \\
\hline $\mathrm{PH}$ & 4.3846 & 0.853 \\
\hline $\mathrm{EC}$ & 18.3102 & 0.650 \\
\hline $\mathrm{OC}$ & -1.3487 & 0.963 \\
\hline Clay & -0.2384 & 0.882 \\
\hline Silt & -0.0610 & 0.971 \\
\hline Sand & -1.7221 & 0.389 \\
\hline K & -0.2491 & 0.365 \\
\hline $\mathrm{P}$ & 5.8969 & 0.263 \\
\hline $\mathrm{N}$ & -30.1243 & 0.636 \\
\hline $\mathrm{Fe}$ & 3.4602 & 0.509 \\
\hline $\mathrm{Zn}$ & -33.0304 & 0.445 \\
\hline $\mathrm{Cu}$ & -17.3814 & 0.693 \\
\hline $\mathrm{Mn}$ & -9.6971 & 0.433 \\
\hline Humidity & -1.2606 & 0.954 \\
\hline Evaporation & -0.3835 & 0.720 \\
\hline
\end{tabular}

Table 4. Results of MLR for investigating the significance of $\beta$.

\begin{tabular}{|c|c|c|}
\hline & Coefficient & P-Value \\
\hline Elevation & 0.0629 & 0.508 \\
\hline Rain & 0.7299 & 0.075 \\
\hline Temperature & 3.7060 & 0.896 \\
\hline $\mathrm{PH}$ & 4.3749 & 0.840 \\
\hline $\mathrm{EC}$ & 18.1040 & 0.557 \\
\hline $\mathrm{OC}$ & -1.2537 & 0.960 \\
\hline Clay & -0.2382 & 0.872 \\
\hline Silt & -0.0586 & 0.969 \\
\hline Sand & -1.7188 & 0.342 \\
\hline K & -0.2484 & 0.307 \\
\hline $\mathrm{P}$ & 5.8871 & 0.214 \\
\hline $\mathrm{N}$ & -29.8105 & 0.545 \\
\hline $\mathrm{Fe}$ & 3.4709 & 0.461 \\
\hline $\mathrm{Zn}$ & -33.0846 & 0.401 \\
\hline $\mathrm{Cu}$ & -17.2099 & 0.638 \\
\hline $\mathrm{Mn}$ & -9.7372 & 0.361 \\
\hline Humidity & -1.4385 & 0.872 \\
\hline Evaporation & -0.3917 & 0.465 \\
\hline
\end{tabular}

Table 5. The results of the first run of BMLR

Table 5 shows the results of the BMLR model after removing $\beta_{0}$ As Table 5 indicates, by considering the effects of other variables, the effect of some factors was not significant (P-Value $>0.05$ ).

Then the most insignificant term (term with the most P-Value) in the first run (Silt) is removed and the operation run again. Table 6 shows the results of the BMLR model after removing Silt. As can be seen in Table 6 , by considering the effect of other factors, some terms are not significant again.

Then the most insignificant term in the second run $(\mathrm{OC})$ is removed and run the operation again. The process is continued step by step to the point that there are only significant terms. Table 7 indicates the summary of excluded variables in the BMLR method in each step.

Table 8 shows the results of the last run. As can be seen in Table 8, the effects of rain, sand, P, Fe, Zn, Mn, and evaporation on the distribution of $S$. pilifera species were significant. Rain, $\mathrm{P}$, and $\mathrm{Fe}$ have positive effects (positive coefficient), and sand, $\mathrm{Zn}, \mathrm{Mn}$, and evaporation have negative effects (negative coefficient).

Therefore, the equation of the final BMLR model was

$$
\begin{gathered}
\text { Canopy Cover }=0.3301 \text { Rain }-1.3765 \text { Sand } \\
+6.1675 \mathrm{P}+2.6558 \mathrm{Fe}-54.4292 \mathrm{Zn}- \\
6.3337 \mathrm{Mn}-0.1511 \text { Evaporation }
\end{gathered}
$$


Table 6. Results of the second run of BMLR.

\begin{tabular}{|c|c|c|}
\hline & Coefficient & P-Value \\
\hline Elevation & 0.0623 & 0.476 \\
\hline Rain & 0.7242 & 0.041 \\
\hline Temperature & 4.2758 & 0.849 \\
\hline PH & 4.4191 & 0.827 \\
\hline $\mathrm{EC}$ & 17.5547 & 0.491 \\
\hline $\mathrm{OC}$ & -0.7520 & 0.970 \\
\hline Clay & -0.1835 & 0.651 \\
\hline Sand & -1.6559 & 0.024 \\
\hline K & -0.2448 & 0.240 \\
\hline $\mathrm{P}$ & 5.9520 & 0.150 \\
\hline $\mathrm{N}$ & -29.1160 & 0.495 \\
\hline $\mathrm{Fe}$ & 3.3913 & 0.389 \\
\hline $\mathrm{Zn}$ & -33.7229 & 0.312 \\
\hline $\mathrm{Cu}$ & -16.3938 & 0.557 \\
\hline $\mathrm{Mn}$ & -9.9082 & 0.273 \\
\hline Humidity & -1.3221 & 0.860 \\
\hline Evaporation & -0.4009 & 0.370 \\
\hline
\end{tabular}

Now, the goodness of the fitted model was assessed by the coefficient of determination $\left(R^{2}\right)$, adjusted coefficient of determination $\left(R^{2}{ }_{a d j}\right)$, root mean square error (RMSE), and residual analysis. A lower RMSE value and higher $R^{2}$ and $R^{2}{ }_{a d j}$ values and independent normal residuals with stable variance are regarded as showing goodness of fitted predictive model. As can be

Table 7. Summary of excluded variables in the BANCOVA method.

\begin{tabular}{|c|c|c|}
\hline Step & $\begin{array}{c}\text { Excluded variable } \\
\text { All variables are } \\
\text { included }\end{array}$ & P-Value \\
\hline 1 & Silt & 0.969 \\
\hline 2 & OC & 0.970 \\
\hline 3 & Humidity & 0.853 \\
\hline 4 & PH & 0.761 \\
\hline 6 & Clay & 0.520 \\
\hline 7 & Temperature & 0.331 \\
\hline 8 & Elevation & 0.388 \\
\hline 9 & EC & 0.208 \\
\hline 10 & Cu & 0.443 \\
\hline 11 & $\mathrm{~N}$ & 0.267 \\
\hline 12 & $\mathrm{~K}$ & 0.158 \\
\hline
\end{tabular}

Table 8 . The results of the last run of BMLR.

\begin{tabular}{|c|c|c|}
\hline & Coefficient & P-Value \\
\hline Rain & 0.3301 & 0.002 \\
\hline Sand & -1.3765 & $<0.001$ \\
\hline $\mathrm{P}$ & 6.1675 & 0.005 \\
\hline Fe & 2.6558 & 0.017 \\
\hline Zn & -54.4292 & 0.006 \\
\hline Mn & -6.3337 & 0.001 \\
\hline Evaporation & -0.1511 & 0.018 \\
\hline
\end{tabular}

Table 9. Indexes for the goodness of fitted BMLR models.

\begin{tabular}{|c|c|c|}
\hline R Square & Adjusted R Square & RMSE \\
\hline 0.999 & 0.998 & 2.1395 \\
\hline
\end{tabular}

seen in Table 9, it seems that the BMLR nicely modeled the canopy cover based on RMSE, $R^{2}$, and $R^{2}$ adi

To investigate the normality of residuals, probability plot and different statistical tests (Anderson-Darling, Kolmogorov-Smirnov, Shapiro-Wilk) were used. As can be seen in Figure 1, the normal probability plot (2) satisfied the normality of residuals, since the points are close to the line. The normality was also satisfied with different statistical tests (P-Value $>0.05$ ).

As Fig. 2 indicates, the plot of residuals versus observations' order was completely random about horizontal axis. Therefore, the independence of residuals is satisfied.

Fig. 3 shows the plot of the residuals versus the fitted values. As can be seen, the points are completely random about of the horizontal axis, and the stability of the variance is satisfied. Therefore, the BMLR nicely modeled the canopy cover.

Cognition of vegetation communities and evaluating their interaction with environments is known as a crucial factor for achieving sustainable rangeland management in order to introduce the appropriate species for reclaiming a degraded area. Furthermore, knowledge about environmental factors can be used to predict success and failure of growing species.

In order to recognize the various native species and vegetation cover associated with them, these species can be used in ecosystem improvement and pastoral ecosystem revival. The present study examined the relationship between environmental variables and $S$. pilifera species distribution in Kohgiluyeh and BoyerAhmad Province in central Zagros, Iran.

Results showed that the effects of rain, sand, P, Fe, $\mathrm{Zn}, \mathrm{Mn}$, and evaporation, on the distribution of $S$. pilifera species were significant. Rain, $\mathrm{P}$, and $\mathrm{Fe}$ have positive effects (positive coefficient), and sand, Zn, $\mathrm{Mn}$, and evaporation have negative effects (negative coefficient). Results showed that the BMLR nicely 


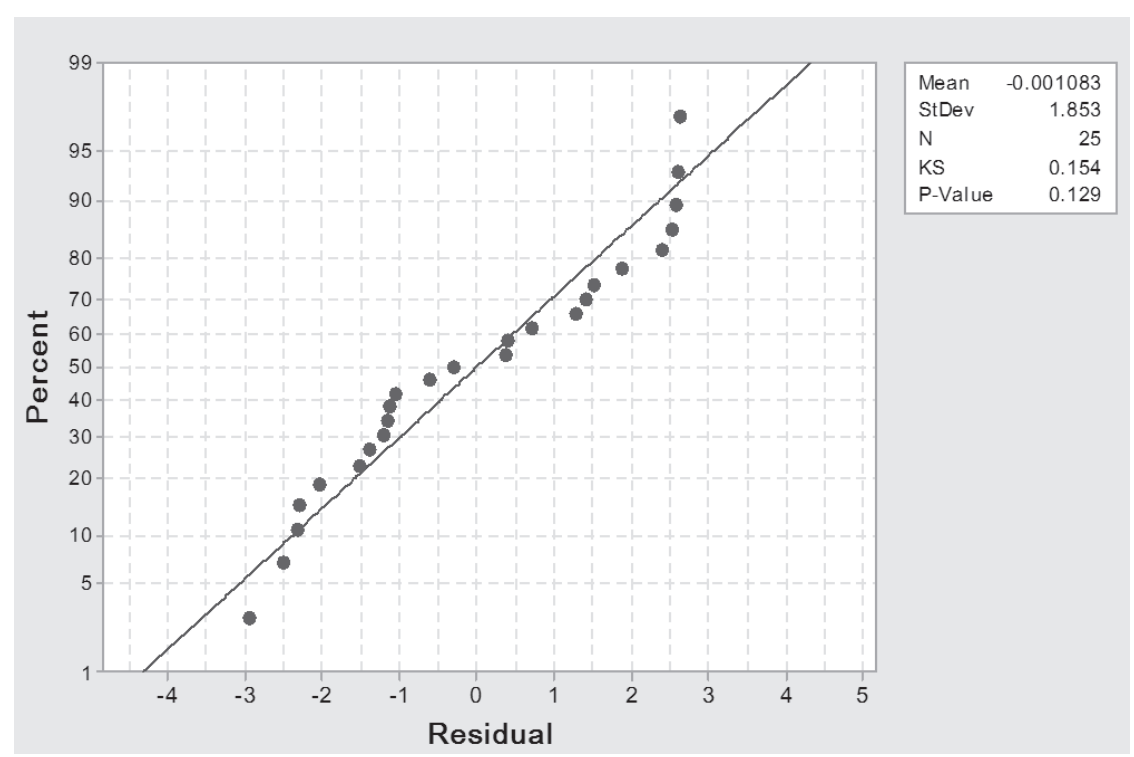

Fig. 1. Normal probability plot of residuals for BMLR model. If the points on the plot depart from a straight line, the normality assumption may be invalid.

modeled the canopy cover based on RMSE, $R^{2}$, and , which were $0.999,0.998$, and 2.1395 , respectively.

The results are in line with the findings of Darvishi et al. (2013). In this regard, Darvishi et al. (2013) investigated a study on the environmental factors contributing to the distribution of Thymus kotschyanus in Taleghan Basin, Iran. Results demonstrated that factors involving slope, altitude, organic matter, lime content, nitrogen content, and soil texture have the highest impact on vegetation characteristics [5].

Our results showed that the most significant factors are rain and evaporation. In this regard Jahantab et al. (2015) have shown that the relationship between number (density) and canopy cover percentage of Kelussia odoratissima mozaff with height, slope, rainfall, and evaporation were statistically meaningful at $95 \%$ confidence interval. Then the factors such as rain and evaporation were important factors on the distribution of plant species [17].

Soil factors play a major role in ecological processes and are closely associated with the growth and distribution of plants. Our results indicated that soil properties such as sand, $\mathrm{P}, \mathrm{Fe}, \mathrm{Zn}$, and Mn were effective in distributing S. pilifera species. In our study area, the differences of climate and topographical features are relatively small, so distribution of $S$. pilifera species may be potentially affected by soil properties. In this regard Zare et al. (2011) stated that soil texture is one of the most effective factors in distributing $Z$. eurypterum, $P$. aucheri, and A. spinosa species [18]. Gholinejad et al. (2012) stated that soil texture is one of the most effective factors in the distribution of As. gossypinus - Gu. tournefortii, Br. tomentellus-Fe. ovina and Fe. hausknekhtii-Pr. Ferulacea [19].

This study shows that organic carbon was not effective on the distribution of S. pilifera species. Based on our results, Komaee et al. (2012) [20], Fahimi-Pour et al. (2010) [21], and Ahmadi et al. (2010) [22] introduced organic matter and depth as the most important soil factors that influence the separation of vegetation types in the study area. Tao et al. (2017) stated that the distribution of herbs on sand dunes was dominantly influenced by sand dune topography (slope position, convexity, and relative height), soil nutrients (total nitrogen and phosphorus), and deep-rooted shrubbery (Ephedra distachya) [23].

Plant species distribution over a high geographical range is controlled by climatic factors - mainly temperature and rainfall. In a small range, species distribution is related to edaphic factors [24]. Therefore, these environmental factors are important not only in detecting plant species distribution variations with spatial scale, but also for providing insight into the environmental requirements of the species needed for

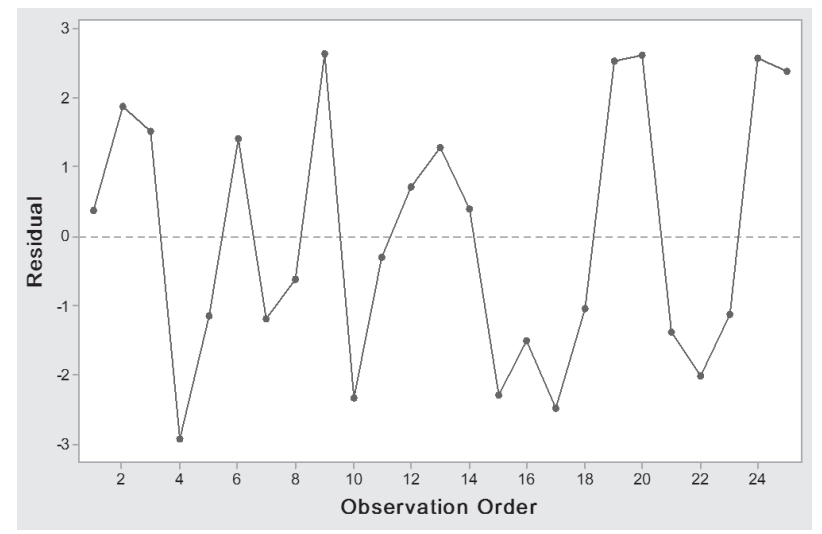

Fig. 2. Plot of residuals versus observation order for BMLR model; this is a plot of all residuals in the order that the data were collected and can be used to find non-random error. 


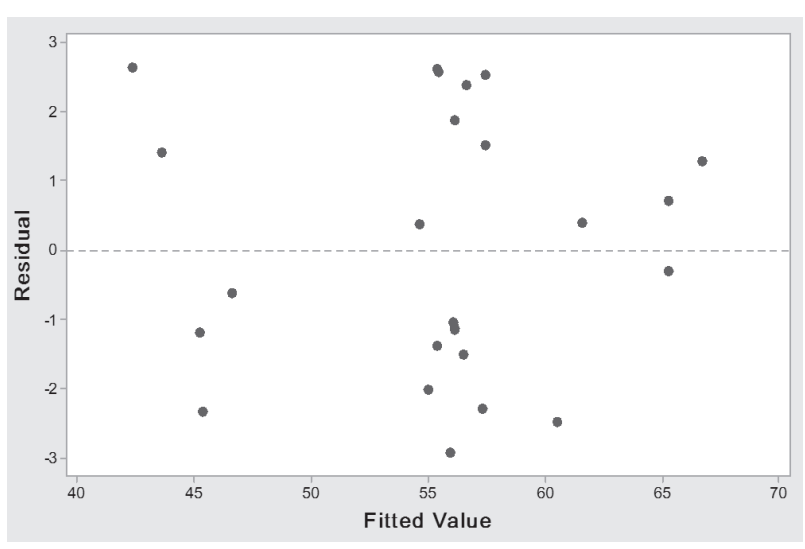

Fig. 3. Plot of residuals versus fitted values for BMLR model.

successful ecological restoration and the establishment of plantations [25].

Our results showed that elevation was not effective distribution of S.pilifera, while some researchers reported that topographic factors are related to vegetation communities, as found previously by many studies [26]. Zhong-hua et al. (2013) showed that topographical factors were more important than edaphic ones in affecting local plant distribution on steep slopes with extensive rock outcrops, while edaphic factors were more influential on gentle slope and relatively thick soil over rock in subtropical karst forest [27].

Schumann et al. (2016) reported that elevation and precipitation were the most influencing environmental factors on potential distributions of both juvenile and adult richness [28]. The appearance of a plant group in a given area isn't accidental, but occurs in response to changes in climatic, topographic, edaphic, and biotic parameters. In fact, vegetation groups are determined by the combined effects of a variety ecological factors.

In this research we investigated the impact of some habitat characteristics on the distribution of S. pilifera Benth using the BMLR model. In this regard, Akhter et al. (2017) stated that the application of the species distribution model may provide policymakers and conservationists with a useful tool for predicting future distribution (at both local and regional scales) of poorly known species with high preservation concerns [29].

Bobrowski et al. (2017) stated that that analyzing and understanding the environmental factors driving the current distribution of Betula utilis is crucial for the prediction of future range shifts of B. utilis and other treeline species, and for deriving appropriate climate change adaptation strategies [30].

\section{Conclusions}

Our study investigated the impact of some habitat characteristics on the distribution of Stachys pilifera Benth, an endemic medicinal plant in Iran, using the BMLR model in Kohgiluyeh and Boyer-Ahmad
Province. The BMLR model showed that environmental factors such as soil (sand, P, Fe, Zn, and $\mathrm{Mn}$ ) and climate (rain and evaporation) are effective for the distribution of S. pilifera species. Rain, sand, $\mathrm{P}, \mathrm{Fe}, \mathrm{Zn}$, $\mathrm{Mn}$, and evaporation have significant effects on the distribution of S. pilifera. Rain, $\mathrm{P}$, and Fe have positive effects, which means that $S$. pilifera will increase with their increase. Sand, $\mathrm{Zn}, \mathrm{Mn}$, and evaporation have negative effects (negative coefficient), in which case $S$. pilifera will decrease with their increase. The present study addressed some aspects of relationships between environmental factors and the distribution of S.pilifera species in Kohgiluyeh and Boyer-Ahmad Province. It was anticipated that this finding could be used as a tool for predicting the probability of existence and the absence of this plant species in similar ecosystems.

\section{Acknowledgements}

This work was supported by the Kohgiluyeh-vaBoyerahmad Agricultural and Natural Resources Research and Education Center. The authors are grateful for all their help and assistance in all aspects of manuscript preparation.

\section{References}

1. KUMAR D., BHAT Z.A., KUMAR V., KHAN N.A., CHASHOO I.A., ZARGAR M.I., SHAH M.Y. Effects of Stachys tibetica essential oil in anxiety. European Journal of Integrative Medicine, 4 (2), e169, 2012.

2. ZARGARI A. Medicinal plants. Tehran: Tehran University Press; 1992.

3. FARJAM M.H., KHALILI M., RUSTAYIAN A., JAVIDNIA K., IZADI S. Biological activity of the n-butanolic extract of Stachys pilifera. African Journal of Microbiology Research., 5 (28), 5115, 2011.

4. JAHANTAB E., SEPEHRI A., BARANI H., QASEMI ARYAN Y., FARAJOLAHI A. An Introduction on the Endangered Medicinal Species of Mountain's Kelavs (Kelussia odoratissima Mozaff.) in Central Zagros in Kohgiluyeh Region, Iran. Journal of Rangeland Science, 2 (1), 409, 2011.

5. DARVISHI L., ZARE CHAHOUKI M.A., JAFARI M., AZARNIVAND H., YOUSEFI VALIKCHALI M. Study on the Environmental Factors Contributing to Distribution of Thymus kotschyanus in Taleghan Basin, Iran. Journal of Rangeland Science, 24; 4 (1), 82, 2013.

6. AHMADI A., SHAHMORADI A.A., ZAREKIA S., AHMADI E., NATEGHI S. Autecological study of Astragalus effusus in rangelands of west Azarbaijan province, Iran. Iranian Journal of Range and Desert Research, 20 (1), 172, 2013.

7. SHARIFI YAZDI M., SHAHMORADI A.A., ZAREKIA S. Autecology of Ferula ovina Boiss in Kerman Province. Journal of redintegrate natural resources, 5 (2), 57, 2014.

8. MIRIRNEJAD S.H., NAJAFPORNAVEEI M., MOHTASHAMI R., DASTYARAN M. Investigation of Atacology of Extinction species Stachys pilifera L. in Kohgiluyeh and Boyer Ahmad Province. National 
Conference on Natural Products and Medicinal Plants, Iran, 2012.

9. HEIDARI H. Identification of Morphological Characteristics and Determination of Essential Oil of Stachys pilifera L. in different habitats of Kohgiluyeh and Boyer Ahmad Province and Study on the Possibility of Potting in Greenhouse. Master's Thesis , faculty of agriculture, university of Yasuj. 2015.

10. BREMNER J.M., MULVANEY C.S. Nitrogen total. Methods of soil analysis. Part 2. Chemical and microbiological properties. (methodsofsoilan2) 595, 1982.

11. KLUTE A. (ed.) Methods of soil analysis. Part I. physical and micrological methods. Second edition. Agronomy series 9, ASA. Madison, Wis, 1986.

12. WALKLEY A., BLACK I.A. An examination of the Degtjareff method for determining soil organic matter, and a proposed modification of the chromic acid titration method. Soil science, 1; 37 (1), 29, 1934.

13. GEE G.W., BAUDER J.W. Particle-size analysis. Methods of soil analysis: Part 1 - Physical and mineralogical methods. (methodsofsoilan1) 383, 1986.

14. OLSEN S.R. Estimation of available phosphorus in soils by extraction with sodium bicarbonate. United States Department of Agriculture; Washington; 1954.

15. HELMKE P.A., SPARKS D.L. Lithium, sodium, potassium, rubidium, and cesium. Methods of Soil Analysis Part 3 - Chemical Methods. (methodsofsoilan3) 551, 1996.

16. PAGE A.L., MILLER R., KEENEY D.R. Part 2: Chemical and microbiological properties. Methods of soil analysis, 595, 1982.

17. JAHANTAB E., SEPEHRY A., MESDAGHI M., BARANI H. Impact of topographic and climatologic factors on Canopy cover percentage and the number of species Kelussia odoratissima mozaff in Kohgiluyeh. Journal of Iranian Plant Ecophysiological Research, 9 (36), 1,2015

18. ZARE S., JAFARI M., TAVILI A., ABBASI H., ROSTAMPOUR M. Relationship between environmental factors and plant distribution in arid and semiarid area (Case Study: Shahriyar Rangelands, Iran). AmericanEurasian Journal of Agriculture \& Environmental Science, 10 (1), 97, 2011.

19. GHOLINEJAD B., FARAJOLLAHI A., POUZESH H. Environmental factors affecting on distribution of plant communities in semiarid areas (Case study: Kamyaran rangelands, Iran). Annals of Biological Research, 3 (8), 3990, 2012.

20. KOMAEE F., HESHMATI GH., CHAHOOKY ZARE M.A. Effect of soil characteristics on the distribution of plant communities in Taleghan pastures. Third National
Student Conference on Rangeland, Watersheds and Desert. Tehran University, Tehran. 2012.

21. FAHIMI POOR A., CHAHOOKY ZARE M.A., TAVILI A. Study of relation some of range plants to environmental factors (case study: Rangelands of Central Taleghan). Jour. Range Management, 4 (1), 32, 2010.

22. AHMADI H., KAMALI N., SALAJEGHE A., JAFARI M., SADEGHIPOUR A. Investigation on some environmental factors influencing distribution of plant species (Case study: Ghara Aghach watershed, Semirom, Iran). Watershed Management Researches Journal, (Pajouhesh \& SAZANDEGI), 88, 55, 2010.

23. TAO Y., WU G.L., ZHANG Y.M. Dune-scale distribution pattern of herbaceous plants and their relationship with environmental factors in a saline - alkali desert in Central Asia. Science of the Total Environment, 15, 576, 473, 2017.

24. AYYAD M.A., EL-GHAREEB R. Micro variations in edaphic factors and species distribution in a Mediterranean salt desert. Oikos, 1, 125, 1972.

25. TOLEDO M., PEÑA-CLAROS M., BONGERS F., ALARCÓN A., BALCÁZAR J., CHUVIÑA J., LEAÑO C., LICONA J.C., POORTER L. Distribution patterns of tropical woody species in response to climatic and edaphic gradients. Journal of Ecology, 1; 100 (1), 253, 2012.

26. CUI B.S., ZHAI H.J., DONG S.K., CHEN B., LIU S.L. Multivariate analysis of the effects of edaphic and topographical factors on plant distribution in the Yilong Lake Basin of Yun-Gui Plateau, China. Canadian Journal of Plant Science, 1; 89 (1), 211, 2009.

27. ZHANG Z.H., HU G., NI J. Effects of topographical and edaphic factors on the distribution of plant communities in two subtropical karst forests, southwestern China. Journal of Mountain Science, 1; 10 (1), 95, 2013.

28. SCHUMANN K., NACOULMA B.M., HAHN K., TRAORÉ S., THIOMBIANO A., BACHMANN Y. Modeling the distributions of useful woody species in eastern Burkina Faso. Journal of Arid Environments, 31 (135), 104, 2016.

29. AKHTER S., MCDONALD M.A., VAN BREUGEL P., SOHEL S., KJÆR E.D., MARIOTT R. Habitat distribution modeling to identify areas of high conservation value under climate change for Mangifera sylvatica Roxb. of Bangladesh. Land Use Policy, 31 (60), 223, 2017.

30. BOBROWSKI M., GERLITZ L., SCHICKHOFF U. Modeling the potential distribution of Betula utilis in the Himalaya. Global Ecology and Conservation, 31 (11), 69, 2017. 